DOI: 10.12731/wsd-2018-4-204-222

УДК 616.12-008.331.1

\title{
ОСОБЕННОСТИ ПОКАЗАТЕЛЕЙ КАЧЕСТВА ЖИЗНИ ДО И ПОСЛЕ ПРОВЕДЕНИЯ ШКОЛЫ ПО АРТЕРИАЛЬНОЙ ГИПЕРТОНИИ У ЛИЦ ПОЖИЛОГО И СТАРЧЕСКОГО ВОЗРАСТА
}

\author{
Алексеев И.А., Харьков Е.И., Иванов А.Г., Яскевич Р.А., \\ Москаленко О.Л.
}

Цель. Изучение особенностей показателей качества жизни до и после проведения школь по артериальной гипертонии (АГ) у лии пожилого и старческого возраста с АГ.

Материалы и методы. Обследовано 105 отбранных для обучения в школе АГ пачиентов в возрасте 45 лет и старше. Обследование включало изучение показателей качества жизни (КЖ) и факторов влияющих на его снижение до и после обучения.

Результаты. По данным проведенного исследования установлено, что общий балл показателя КЖ до и после проведения школь по АГ соответствовал снижению КЖ легкой степени и не имел различий между анализируемыми группами. Некоторые различия отмечались в группе пожилого возраста по ограничению в занятиях физкультурой и спортом и в группе старческого возраста по отночению близких. После проведения школь по АГ отмечалось повышение прочента лии имеюших нормальные уровни КЖ в группах сравнения и пожилого возраста. Результаты оценки полученных знаний в школе пациентов с АГ у лии старческого возраста (18,73 баллов) были сопоставимы с паџиентами пожилого возраста (19,12 баллов) и группы сравнения (20,16 баллов), что доказывает иелесообразность проведения школ по АГ у лии данного возраста.

Заключение. Результаты проведенного исследования позволяют сделать выводы о иелесообразности проведения школ по АГ среди лии пожилого и старческого возраста.

Ключевые слова: артериальная гипертония; качество жизни; пожилой и старческий возраст. 


\title{
FEATURES OF THE QUALITY OF LIFE BEFORE AND AFTER THE SCHOOL OF ARTERIAL HYPERTENSION AT THE PERSONS OF THE AGE AND SENIOR AGE
}

\author{
Alekseev I.A., Kharkov E.I., Ivanov A.G., Yaskevich R.A., \\ Moskalenko O.L.
}

The purpose of the study. The study of the characteristics of quality of life indicators before and after the school on arterial hypertension (AH) in elderly and senile patients with AH.

Materials and methods. 105 patients selected for study at school were examined at the age of 45 years and older. The survey included the study of quality of life (QoL) and factors affecting its decline before and after training.

Results. According to the study, it was found that the total score of QoL be-

fore and after the school on hypertension corresponded to a decrease in QoL of mild degree and did not differ between the compared groups. Some differences were noted in the elderly group in terms of restriction in physical education and sports and in the group of senile age relative. After the school on AH, there was an increase in the percentage of people with normal QoL levels in the comparison and old age groups. The results of the assessment of the acquired knowledge in the school of patients with AH in the elderly (18,73 points) were comparable with elderly patients (19,12 points) and the comparison group (20,16 points), which proves the feasibility of schools on AH in individuals of this age.

Conclusion. The results of this study allow us to draw conclusions about the advisability of holding schools of the AH among elderly and senile age groups.

Keywords: arterial hypertension; quality of life; elderly and senile age.

\section{Введение}

Несмотря на значительный прогресс в диагностике и лечении, сердечно-сосудистые заболевания (СС3) являются основной причиной заболеваемости, инвалидности и преждевременной смерти в развитых странах, в том числе и в России $[23,28,33,34]$. Артериальная гипертония (АГ) является одним из важнейших факторов риска сердечно-сосудистых заболеваний $[29,30]$. Актуальность проблемы артериальной гипертонии в пожилом возрасте определяется ее высокой популяционной частотой, влиянием на состояние здоровья, работоспособность и продолжи- 
тельность жизни $[1,8,19,20]$. АГ по различным оценкам встречается у 30-50\% лиц старше 60 лет и вносит существенный вклад в развитие и прогрессирование инфаркта миокарда, инсульта, хронической сердечной недостаточности, у пожилых пациентов [7, 18].

Одним из методов оценки эффективности оказания медицинской помощи является исследование и оценка качества жизни (КЖ) больных [3, $4,13]$. Повышенный интерес к исследованиям качества жизни в пожилом и старческом возрасте связан с тем, что здоровье человека в этих возрастных периодах уязвимо и в значительной степени связано с качеством жизни $[9,10,11,14]$. В пожилом и старческом возрасте распространены возрастно-ассоциированные заболевания, происходят изменения в функционировании многих органов и систем на фоне полиморбидности $[4$, $12,16,17,25]$, в связи с чем в последнее время как за рубежом [31, 32], так и в России получила распространение комплексная гериатрическая оценка состояния людей пожилого и старческого возраста $[15,21]$, при которой большое внимание уделяется состоянию качества жизни и его компонентов [24, 27, 35]. В настоящее время наиболее современным подходом к решению проблем, связанных с немедикаментозной коррекцией хронических неинфекционных заболеваний, является организация системы обучения больных и членов их семей в школе здоровья [22]. Эффективность лечения больного артериальной гипертонией напрямую связана с уровнем его знаний о своем заболевании, в связи с этим одним из базисных принципов терапии больных гипертонической болезнью является организация образовательных центров $[6,12]$. Создание для этих целей «Школ артериальной гипертонии» повышает эффективность терапии и значительно улучшает качество жизни больного $[2,26]$. В связи с чем большой интерес вызывает изучение показателей КЖ до и после проведения школы по АГ у лиц пожилого и старческого возраста.

\section{Цель исследования}

Анализ особенностей показателей качества жизни до и после проведения школы по артериальной гипертонии у лиц пожилого и старческого возраста с АГ.

\section{Материалы и методы}

Обследовано 535 пациентов с АГ ІІ-ІІІ стадии (по рекомендациям ВНОК-2013 и ESH/ESC-2013) в возрасте от 45 лет и старше. Из них 246

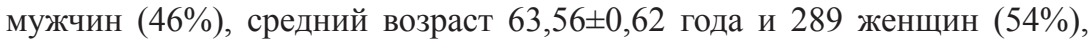


средний возраст $66,67 \pm 0,58$ лет. В соответствии с поставленными задачами обследуемые были разделены на 3 возрастные группы, согласно классификации ВОЗ (1963 г.) - пожилого возраста (60-74 года), старческого (75 лет и старше) и группы сравнения (45-59 лет).

Протокол исследования включал: клинические, инструментальные и лабораторные методы исследования.

Школы по АГ проводились на базе кардиологического отделения КГБУЗ «Красноярская краевая больница №2». Численность группы пациентов составляла 8-10 человек. Программа обучения включала в себя 8 занятий продолжительностью по 90 минут каждое.

На первом и заключительном занятии проводилось исследование КЖ. Для исследования КЖ использовалась методика, разработанная Гладковым А.Г., Зайцевым В.П., Ароновым Д.М. (1982). Данная методика направлена на определение отношения больного сердечно-сосудистым заболеванием к изменениям в его жизни. Методика состоит из 17 вопросов, включающих в себя ограничение больного в физической, умственной, трудовой деятельности, изменение взаимоотношений в семье и друзьями, а также ограничением в проведении досуга, занятия физической культурой и спортом, половой жизнью. Обследуемому предлагается на выбор 4 варианта ответа: «очень переживаю», «мне это неприятно», «отношусь безразлично», «рад этому». Каждому ответу приписывается определенный балл $(-2,-1,0$ или +1 соответственно). За нормативные показатели КЖ принимали значение КЖ, равные 0 или превышающие его. Показатели от -2 до -4 баллов расценивались как снижение КЖ в легкой степени; от -5 до -7 - умеренное снижение КЖ. За значительное снижение КЖ принимали показатели $\leq-8$ баллов.

Статистическая обработка результатов исследования осуществлялась с помощью пакета программ SPPS 22.0. Описательные статистики представлены абсолютными и относительными значениями, средними величинами со стандартной ошибкой при нормальном распределении и медианой с перцентилями $(0,25,0,75)$ при ненормальном распределении. При множественных сравнениях между пациентами разных возрастных групп (независимых выборок) и при ненормальном распределении применялся однофакторный дисперсионный анализ Краскелла-Уоллиса. Статистически значимыми считали различия при $\mathrm{p}<0,05$.

\section{Результаты и обсуждение}

Для проведения школы по АГ, от общего числа обследованных методом случайных чисел было отобрано 105 (19,6\%) пациентов с АГ. Все отобран- 
ные пациенты были распределены по возрасту и полу (Рис. 1). Средний

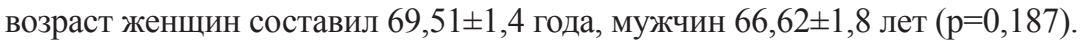

В пределах каждой возрастной группы у всех выбранных пациентов было проведено сравнение показателей КЖ до и после проведения школы по АГ (Табл. 1). КЖ сравнивалось по значению общего показателя, так и по отдельным показателям: необходимость лечиться, ограничения вследствие заболевания, отношение близких, отношение друзей, сослуживцев, ограничения на работе, понижение заработной платы, понижение в должности, ограничение в проведении досуга, ограничение встреч с друзьями или близкими, ограничение в занятиях физкультурой и спортом, уменьшение активности в повседневной жизни, ограничение в питании, ограничение курения или отказ от курения, ограничение в половой жизни (Табл. 2).

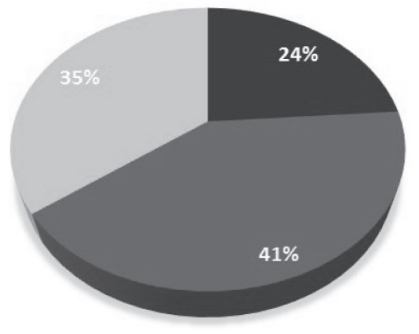

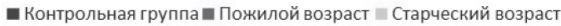

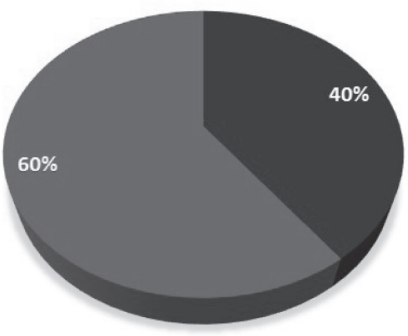

- Мужчины

шенщины

Рис. 1. Возрастно-половой состав пациентов отобранных для проведения школы по АГ

Установлено, что по общему показателю КЖ статистически значимых различий между сравниваемыми группами выявлено не было. Отмечается незначительное повышение общего среднего балла в группе пожилого возраста: до школы: $-2,88 \pm 3,311$, после школы: $-2,49 \pm 3,312,(p=0,413)$ (Табл. 1).

Таблицуа 1.

Значение общего показателя КЖ (баллы) до и после проведения школы по АГ

\begin{tabular}{|l|c|c|c|}
\hline \multicolumn{1}{|c|}{ Группа } & $\begin{array}{c}\text { КЖ до проведения } \\
\text { школы АГ }\end{array}$ & $\begin{array}{c}\text { КЖ после проведения } \\
\text { школы АГ }\end{array}$ & $p$ \\
\hline Контрольная группа & $-1,88 \pm 2,666$ & $-1,84 \pm 2,672$ & $p=0,914$ \\
\hline Пожилой возраст & $-2,88 \pm 3,311$ & $-2,49 \pm 3,312$ & $p=0,413$ \\
\hline Старческий возраст & $-2,11 \pm 3,213$ & $-2,59 \pm 3,826$ & $p=0,742$ \\
\hline
\end{tabular}


При исследовании КЖ до и после проведения школы по АГ по отдельным показателям статистически значимых различий также выявлено не было (Табл. 2).

Некоторые различия отмечались в группе пожилого возраста по ограничению в занятиях физкультурой и спортом (до школы: $-0,37 \pm 0,082$, после школы: $-0,26 \pm 0,067, \mathrm{p}=0,059)$ и в группе старческого возраста по отношению близких (до школы: $-0,03 \pm 0,027$, после школы: $-0,16 \pm 0,073, \mathrm{p}=0,059$ ).

Таблицуа 2.

Значения отдельных показателей КЖ (баллы) до и после проведения школы по АГ

\begin{tabular}{|c|c|c|c|c|c|c|}
\hline ГРУППА & \multicolumn{2}{|c|}{$\begin{array}{c}\text { Группа сравнения } \\
\qquad(\mathrm{n}=25)\end{array}$} & \multicolumn{2}{|c|}{$\begin{array}{c}\text { Пожилой возраст } \\
(\mathrm{n}=43)\end{array}$} & \multicolumn{2}{|c|}{$\begin{array}{c}\text { Старческий } \\
\text { возраст } \\
(n=37)\end{array}$} \\
\hline $\begin{array}{l}\text { Причины } \\
\text { снижения }\end{array}$ & $\begin{array}{c}\text { До } \\
\text { школы }\end{array}$ & $\begin{array}{l}\text { После } \\
\text { школы }\end{array}$ & $\begin{array}{c}\text { До } \\
\text { школы }\end{array}$ & $\begin{array}{l}\text { После } \\
\text { школы }\end{array}$ & $\begin{array}{c}\text { До } \\
\text { школы }\end{array}$ & $\begin{array}{l}\text { После } \\
\text { школы }\end{array}$ \\
\hline $\begin{array}{l}\text { Необходимость } \\
\text { лечиться }\end{array}$ & $-0,24 \pm 0,11$ & $-0,24 \pm 0,10$ & $-0,42 \pm 0,12$ & $-0,37 \pm 0,11$ & $-0,41 \pm 0,11$ & $-0,38 \pm 0,11$ \\
\hline$p$ & \multicolumn{2}{|c|}{$\mathrm{P}=1,0$} & \multicolumn{2}{|c|}{$\mathrm{P}=0,581$} & \multicolumn{2}{|c|}{$\mathrm{P}=0,655$} \\
\hline $\begin{array}{l}\text { Ограничение } \\
\text { вследствие } \\
\text { заболевания }\end{array}$ & $-0,28 \pm 0,09$ & $-0,28 \pm 0,09$ & $-0,35 \pm 0,07$ & $-0,35 \pm 0,07$ & $-0,38 \pm 0,09$ & $-0,35 \pm 0,08$ \\
\hline$p$ & \multicolumn{2}{|c|}{$\mathrm{P}=0,1$} & \multicolumn{2}{|c|}{$\mathrm{P}=0,1$} & \multicolumn{2}{|c|}{$\mathrm{P}=0,564$} \\
\hline $\begin{array}{l}\text { Отношения } \\
\text { близких }\end{array}$ & $-0,08 \pm 0,05$ & $-0,08 \pm 0,05$ & $-0,05 \pm 0,05$ & $-0,09 \pm 0,06$ & $-0,03 \pm 0,03$ & $-0,16 \pm 0,07$ \\
\hline$p$ & \multicolumn{2}{|c|}{$\mathrm{P}=0,1$} & \multicolumn{2}{|c|}{$\mathrm{P}=0,317$} & \multicolumn{2}{|c|}{$\mathrm{P}=0,059$} \\
\hline $\begin{array}{l}\text { Отношение дру- } \\
\text { зей, сослуживцев }\end{array}$ & $-0,08 \pm 0,05$ & $-0,08 \pm 0,05$ & $-0,02 \pm 0,02$ & $-0,07 \pm 0,05$ & $-0,03 \pm 0,03$ & $-0,08 \pm 0,06$ \\
\hline$p$ & \multicolumn{2}{|c|}{$\mathrm{P}=0,1$} & \multicolumn{2}{|c|}{$\mathrm{P}=0,317$} & \multicolumn{2}{|c|}{$\mathrm{P}=0,317$} \\
\hline $\begin{array}{l}\text { Ограничения } \\
\text { на работе }\end{array}$ & $-0,04 \pm 0,07$ & $0,00 \pm 0,06$ & $-0,16 \pm 0,07$ & $-0,16 \pm 0,08$ & $-0,14 \pm 0,07$ & $-0,19 \pm 0,08$ \\
\hline$p$ & \multicolumn{2}{|c|}{$\mathrm{P}=0,317$} & \multicolumn{2}{|c|}{$\mathrm{P}=0,1$} & \multicolumn{2}{|c|}{$\mathrm{P}=0,157$} \\
\hline $\begin{array}{l}\text { Понижение } \\
\text { заработной платы }\end{array}$ & $-0,08 \pm 0,05$ & $0,0 \pm 0,0$ & $-0,26 \pm 0,08$ & $-0,23 \pm 0,08$ & $-0,16 \pm 0,07$ & $-0,16 \pm 0,07$ \\
\hline$p$ & \multicolumn{2}{|c|}{$\mathrm{P}=0,157$} & \multicolumn{2}{|c|}{$\mathrm{P}=0,317$} & \multicolumn{2}{|c|}{$\mathrm{P}=1,0$} \\
\hline $\begin{array}{l}\text { Понижение } \\
\text { в должности }\end{array}$ & $-0,04 \pm 0,04$ & $-0,04 \pm 0,04$ & $-0,19 \pm 0,07$ & $-0,16 \pm 0,07$ & $-0,14 \pm 0,07$ & $-0,16 \pm 0,07$ \\
\hline$p$ & \multicolumn{2}{|c|}{$\mathrm{P}=1,0$} & \multicolumn{2}{|c|}{$\mathrm{P}=0,317$} & \multicolumn{2}{|c|}{$\mathrm{P}=0,317$} \\
\hline $\begin{array}{l}\text { Ограничение } \\
\text { досуга }\end{array}$ & $-0,08 \pm 0,08$ & $-0,08 \pm 0,08$ & $-0,07 \pm 0,04$ & $-0,05 \pm 0,03$ & $-0,03 \pm 0,06$ & $-0,03 \pm 0,07$ \\
\hline$p$ & \multicolumn{2}{|c|}{$\mathrm{P}=1,0$} & \multicolumn{2}{|c|}{$\mathrm{P}=0,317$} & \multicolumn{2}{|c|}{$\mathrm{P}=1,0$} \\
\hline
\end{tabular}


Окончание табл. 2.

\begin{tabular}{|c|c|c|c|c|c|c|}
\hline $\begin{array}{l}\text { Снижение } \\
\text { контактов } \\
\text { с друзьями }\end{array}$ & $-0,08 \pm 0,05$ & $-0,08 \pm 0,05$ & $-0,19 \pm 0,07$ & $-0,14 \pm 0,05$ & $-0,11 \pm 0,06$ & $-0,19 \pm 0,085$ \\
\hline$p$ & \multicolumn{2}{|c|}{$\mathrm{P}=1,0$} & \multicolumn{2}{|c|}{$\mathrm{P}=0,414$} & \multicolumn{2}{|c|}{$\mathrm{P}=0,18$} \\
\hline $\begin{array}{l}\text { Снижение } \\
\text { физической } \\
\text { активности }\end{array}$ & $-0,24 \pm 0,13$ & $-0,28 \pm 0,14$ & $-0,37 \pm 0,08$ & $-0,26 \pm 0,07$ & $-0,24 \pm 0,1$ & $-0,24 \pm 0,1$ \\
\hline$p$ & \multicolumn{2}{|c|}{$\mathrm{P}=0,317$} & \multicolumn{2}{|c|}{$\mathrm{P}=0,059$} & \multicolumn{2}{|c|}{$\mathrm{P}=1,0$} \\
\hline $\begin{array}{l}\text { Снижение актив- } \\
\text { ности в быту }\end{array}$ & $-0,36 \pm 0,13$ & $-0,4 \pm 0,13$ & $-0,53 \pm 0,09$ & $-0,49 \pm 0,09$ & $-0,38 \pm 0,1$ & $-0,46 \pm 0,11$ \\
\hline$p$ & \multicolumn{2}{|c|}{$\mathrm{P}=0,317$} & \multicolumn{2}{|c|}{$\mathrm{P}=0,414$} & \multicolumn{2}{|c|}{$\mathrm{P}=0,257$} \\
\hline $\begin{array}{l}\text { Ограничение } \\
\text { в питании }\end{array}$ & $-0,2 \pm 0,129$ & $-0,24 \pm 0,12$ & $-0,21 \pm 0,1$ & $-0,09 \pm 0,09$ & $-0,05 \pm 0,08$ & $-0,03 \pm 0,07$ \\
\hline$p$ & \multicolumn{2}{|c|}{$\mathrm{P}=0,564$} & \multicolumn{2}{|c|}{$\mathrm{P}=0,236$} & \multicolumn{2}{|c|}{$\mathrm{P}=0,564$} \\
\hline Отказ от курения & $-0,04 \pm 0,07$ & $0,00 \pm 0,06$ & $0,00 \pm 0,03$ & $0,00 \pm 0,03$ & $-0,03 \pm 0,03$ & $-0,08 \pm 0,06$ \\
\hline$p$ & \multicolumn{2}{|c|}{$\mathrm{P}=0,655$} & \multicolumn{2}{|c|}{$\mathrm{P}=1,0$} & \multicolumn{2}{|c|}{$\mathrm{P}=0,317$} \\
\hline $\begin{array}{l}\text { Изменение } \\
\text { в половой жизни }\end{array}$ & $-0,04 \pm 0,04$ & $-0,04 \pm 0,04$ & $-0,07 \pm 0,05$ & $-0,02 \pm 0,02$ & $0,00 \pm 0,00$ & $-0,08 \pm 0,08$ \\
\hline$p$ & \multicolumn{2}{|c|}{$\mathrm{P}=1,0$} & \multicolumn{2}{|c|}{$\mathrm{P}=0,32$} & \multicolumn{2}{|c|}{$\mathrm{P}=0,28$} \\
\hline
\end{tabular}

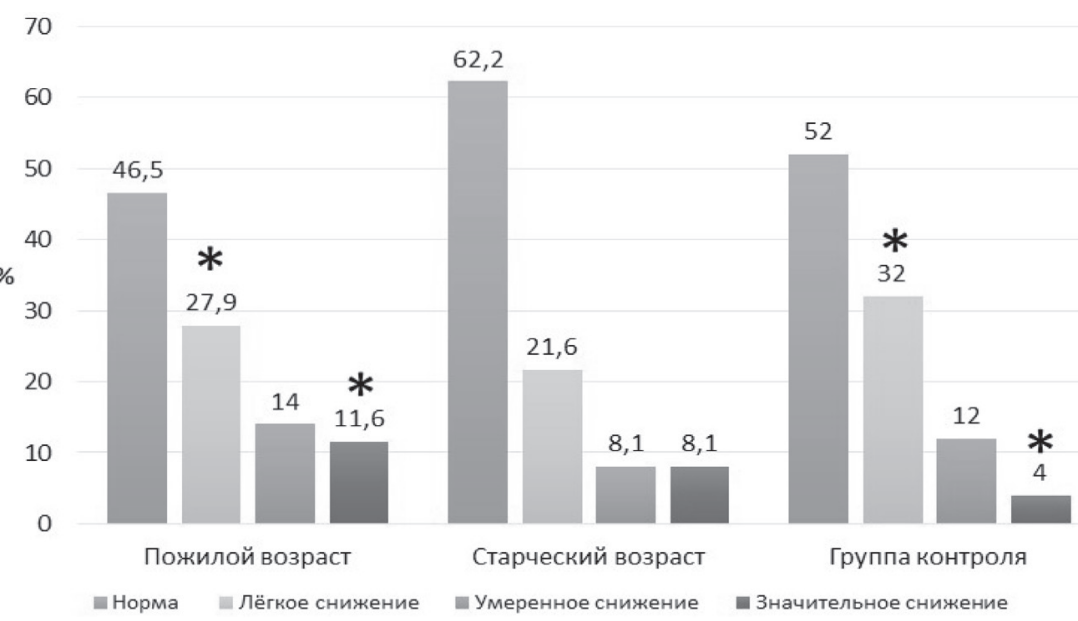

Рис. 2. Уровни показателей КЖ до проведения школы по АГ.

* - уровень значимости различий между группами контроля и пожилого возраста

До проведения школы по АГ во всех сравниваемых группах преобладал нормальный уровень КЖ. По лёгкому снижению КЖ статистиче- 
ски значимые различия были у группы сравнения и пожилого возраста (32\% и 27,9\%, p=0,028). По значительному снижению КЖ достоверно отличались группа пожилого возраста и группа сравнения $(11,6 \%$ и $4 \%$, $\mathrm{p}=0,028)$. Таким образом, наибольший процент по значительному снижению КЖ наблюдался в группе пожилого возраста. По умеренному снижению КЖ также был наибольший уровень у лиц пожилого возраста, но это не достигало статистической значимости $(\mathrm{p}=0,546)$ (Рис. 2).

После проведения школы по АГ повысился процент нормального уровня КЖ в группах сравнения и пожилого возраста (52\% и $60 \%$, $\mathrm{p}=0,000,46,5 \%$ и $51,2 \%, \mathrm{p}=0,000)$. В группе старческого возраста прирост процента нормального уровня не достигает статистической значимости $(62,2 \%$ и $64,9 \%, \mathrm{p}=0,913)$. В группе пожилого возраста отмечается достоверное снижение процента значительного снижения КЖ $(11,6 \%$ и $7 \%, \mathrm{p}=0,032)$. В группе старческого возраста отмечается повышение процента значительного снижения КЖ $(8,1 \%$ и $13,5 \%, p=0,027)$, что считаем возможным объяснить изначально низким уровнем знаний у лиц данного возраста об АГ и её осложнениях.

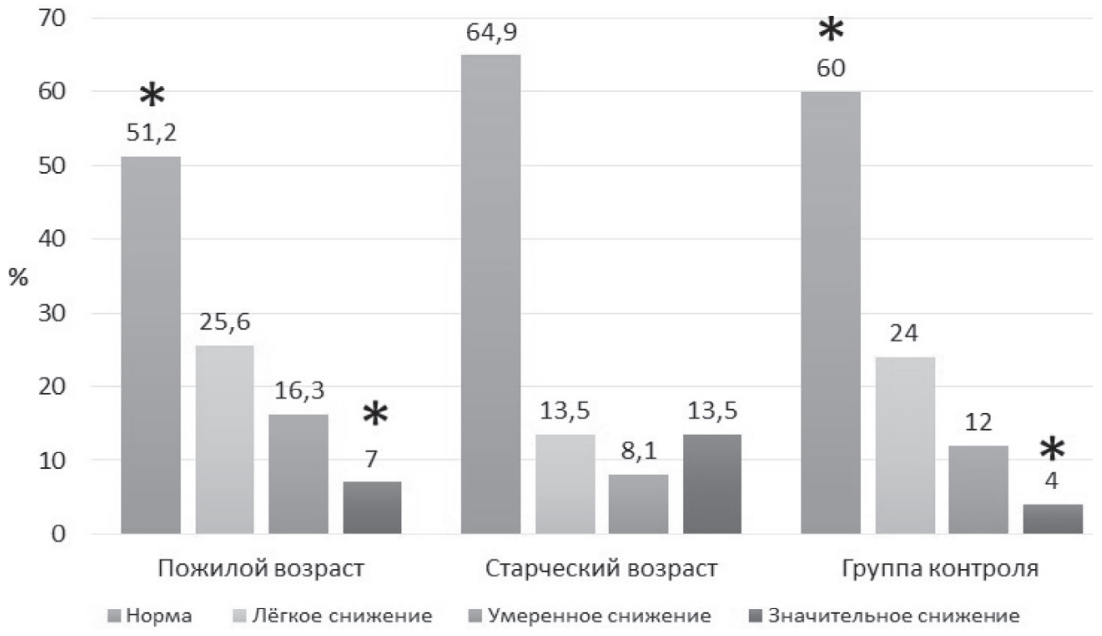

Рис. 3. Уровни показателей КЖ после проведения школы по АГ.

* - уровень значимости различий между группами контроля и пожилого возраста

Таким образом, в группе пожилого возраста после проведения школы по АГ отмечалось достоверное снижение процента значительного снижения КЖ. 
По окончании программы обучения в школе по АГ пациенты заполняли опросники по оценке проведения школы и полученных знаний, описанные в организационно-методическом письме «Организация школ здоровья для пациентов с артериальной гипертонией в первичном звене здравоохранения» (Оганов Р.Г. с соавт. 2002).

Достоверных различий по оценке полученных знаний между возрастными группами найдено не было. Средний балл в группе старческого возраста достоверно не был ниже ни по сравнению с группой пожилого возраста, ни с группой сравнения.

20,5

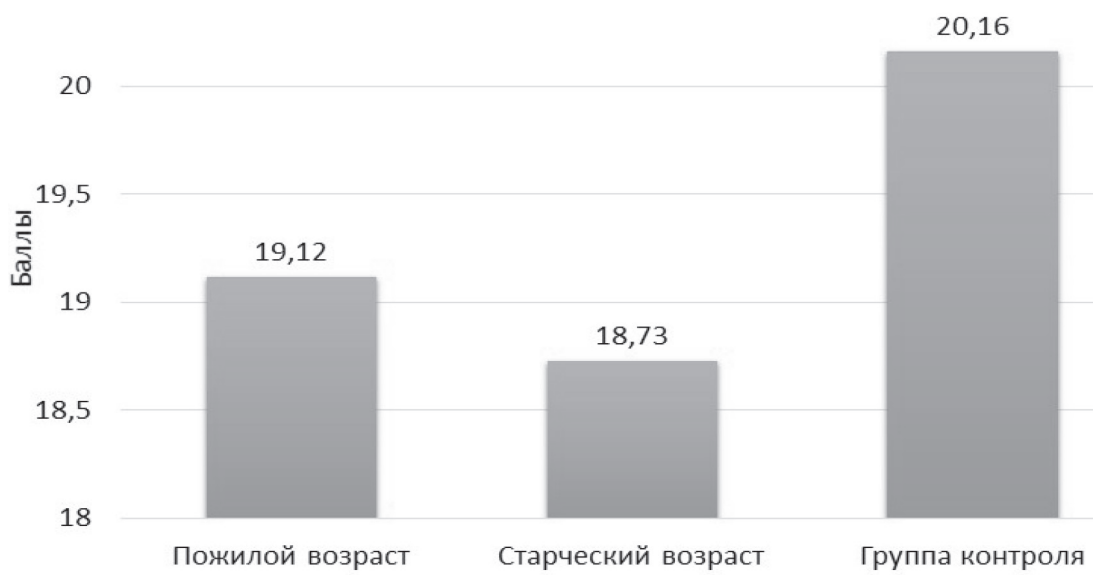

Рис. 4. Оценка знаний после проведения школы по АГ

При анализе знаний по отдельным вопросам по большинству вопросов достоверных различий между возрастными группами найдено не было. Достоверно отличались средние баллы по следующим позициям: «Повышению АД способствует избыточная масса тела» (старческий возраст: $0,89 \pm 0,315$, пожилой возраст: $1,00 \pm 0,000, \mathrm{p}=0,044$, старческий возраст: $0,89 \pm 0,315$, группа сравнения: $1,00 \pm 0,000, p=0,044)$, «Повышению АД способствует курение» (старческий возраст: $0,89 \pm 0,315$, группа сравнения: $1,00 \pm 0,000, \mathrm{p}=0,044)$, что, по нашему мнению, может быть связано с более низкой распространённостью данных ФР среди лиц старческого возраста.

Также были найдены достоверные различия по пунктам «Знаете ли Вы свою массу тела» (группа сравнения: $1,00 \pm 0,000$, пожилой возраст: $0,91 \pm 0,294, \mathrm{p}=0,044$, группа сравнения: $1,00 \pm 0,000$, старческий возраст: 
$0,89 \pm 0,315, \mathrm{p}=0,044)$, «Знаете ли Вы свой уровень холестерина» (группа сравнения: $1,00 \pm 0,000$, пожилой возраст: $0,86 \pm 0,351, \mathrm{p}=0,013$, группа сравнения: $1,00 \pm 0,000$, старческий возраст: $0,86 \pm 0,347, \mathrm{p}=0,023)$. По нашему мнению, более высокий балл в группе сравнения связан с большей осведомлённостью данной возрастной группы о факторах риска АГ посредством средств массовой информации и сети Интернет.

\section{Заключение}

Резюмируя вышеизложенное, следует отметить, что общий балл показателя КЖ до и после проведения школы по АГ соответствовал снижению КЖ легкой степени и не имел различий между анализируемыми группами. Некоторые различия отмечались в группе пожилого возраста по ограничению в занятиях физкультурой и спортом и в группе старческого возраста по отношению близких. После проведения школы по АГ повысился процент нормального уровня КЖ в группах сравнения и пожилого возраста.

Результаты оценки полученных знаний в школе пациентов с АГ у лиц старческого возраста (18,73 баллов) были сопоставимы с пациентами пожилого возраста (19,12 баллов) и группы сравнения (20,16 баллов), что доказывает целесообразность проведения школ по АГ у лиц данного возраста.

\section{Список литературы}

1. Артюхов И.П., Давыдов Е.Л., Капитонов В.Ф., Харьков Е.И. Социально-экономическая характеристика больных с артериальной гипертонией старших возрастных групп // Сибирское медицинское обозрение. 2013. №6. С. 78-83.

2. Беляева А.К., Мультановский Б.Л., Шабардина С.В. и др. Эффективность работы школы здоровья для пациентов с артериальной гипертонией // Здоровье, демография, экология финно-угорских народов. 2013. №4. С. 29-31.

3. Вологдина И.В., Федорец В.Н., Порошина Е.Г. Оценка психосоматических особенностей и качества жизни у пациентов старческого возраста с хронической сердечной недостаточностью // Клиническая больница. 2012. № 2-3. C. 45-48.

4. Вологдина И.В., Минько Б.А., Крылова М.П., Порошина Е.Г. Качество жизни и тревожно-депрессивные нарушения у больных пожилого возраста с фибрилляцией предсердий // Вестник Межнационального центра исследования качества жизни. 2016. № 27-28. С. 37-43.

5. Гарганеева Н.П., Петрова М.М., Евсюков А.А. и др. Влияние депрессии на течение ишемической болезни сердца и качество жизни пациентов // Клиническая медицина. 2014. № 12. С. 30-37. 
6. Давыдов Е.Л., Горянец Д.И., Кожевников И.А. и др. Особенности представлений о проблемах жизни с артериальной гипертонией пациентов старших возрастных групп // Медицинский вестник МВД. 2012. № 5 (60). С. 25-30.

7. Давыдов Е.Л., Яскевич Р.А., Кусаев В.В., Алексеев И.А. Проблемы приверженности к лечению пациентов старших возрастных групп с артериальной гипертонией в г. Красноярске в рамках организационно-функциональной модели медико-социальной помощи // Международный журнал экспериментального образования. 2016. № 5-3. С. 285-289.

8. Давыдов Е.Л., Яскевич Р.А., Мажаров В.Ф. Факторы, препятствующие приобретению пациентами старших возрастных групп лекарственных средств для лечения артериальной гипертонии // Международный журнал экспериментального образования. 2016. № 5-3. С. 290-295.

9. Кадырова Д.А., Сафохонов Д.Т., Ганиева Ф.С., Ишанкулова Г.А. Качество жизни больных пожилого и старческого возраста с артериальной гипертонией // Сибирский медицинский журнал (Иркутск). 2014. № 3. С. 58-61.

10. Корнилова М.В. Качество жизни и социальные риски пожилых // Современные исследования социальных проблем (электронный научный журнал). 2011. Т. 7. №3. С. 78-88.

11. Мелёхин А.И. Качество жизни в пожилом и старческом возрасте: проблемные вопросы // Современная зарубежная психология. 2016. Том 5. № 1. С. 53-63.

12. Плавунов Н.Ф., Фомина А.В. Изучение информированности пациентов, посещающих школу артериальной гипертонии, о своем заболевании // Вестник Российского университета дружбы народов. Серия: Медицина. 2004. № 2. C. 81-82.

13. Приступа Е.Н., Павлова Ю.А. Исследование качества жизни разных возрастных групп населения // Наука и спорт: современные тенденции. 2013. T.1, № 1. C. 12-21.

14. Ремизов Е.В., Давыдов Е.Л., Корепина Т.В. Проблемы качества жизни пациентов старших возрастных групп с артериальной гипертонией // Военно-медицинский журнал. 2012. № 5. С. 64.

15. Тихонова Н.В., Добрецова Е.А., Астанина Н.Г., Ильюшенко В.М. Психологический аспект качества жизни пожилого населения Красноярского края // Медицина и образование в Сибири. 2014. № 4. С. 64.

16. Филимонова Л.А., Давыдов Е.Л., Яскевич Р.А. Психосоматические проблемы пациентов старших возрастных групп с артериальной гипертонией // Современные проблемы науки и образования. 2016. № 3. С. 106.

17. Харьков Е.И., Давыдов Е.Л. Особенности качества жизни и психологические характеристики больных пожилого возраста с заболеваниями сер- 
дечно-сосудистой системы и пути коррекции последних // Российский кардиологический журнал. 2010. № 3 (83). С. 53-57.

18. Харьков Е.И., Давыдов Е.Л., Гринштейн Ю.И., Кусаев В.В. Особенности фармакотерапии в пожилом и старческом возрасте. Сообщение II // Сибирский медицинский журнал (Иркутск). 2010. Т 99, №8. С. 174-177.

19. Харьков Е.И., Давыдов Е.Л., Шульмин А.В. Пожилой пациент и артериальная гипертония: особенности течения и терапии (Сообщение I) // Сибирское медицинское обозрение. 2010. № 3 (63). С. 3-8.

20. Харьков Е.И., Давыдов Е.Л., Шульмин А.В. Пожилой пациент и артериальная гипертония: особенности течения и терапии (Сообщение II) // Сибирское медицинское обозрение. 2010. № 3 (65). С. 3-7.

21. Шульмин А.В., Тихонова Н.В., Аверченко Е.А. и др. Качество жизни населения как компонент перспективного развития муниципального здравоохранения // Медицина в Кузбассе. 2011. № 2. С. 8-12.

22. Шупина М.И., Логинова Е.Н. Перспективы использования образовательных программ в немедикаментозной коррекции артериальной гипертонии // Казанский медицин ский журнал. 2007. Т.88,№5, приложение. С. 160-164.

23. Щербакова Е.М. Россия: предварительные демографические итоги 2016 года (часть II) // Демоскоп Weekly. 2017. № 717-718. C. 21-30.

24. Яскевич Р.А. Особенности показателей качества жизни в различные периоды реадаптации к новым климатическим условиям у пожилых мигрантов Крайнего Севера с артериальной гипертонией // Клиническая геронтология. 2017. Т. 23. № 9-10. С. 81-83.

25. Яскевич Р.А., Давыдов Е.Л. Медико-социальные проблемы качества жизни геронтов с артериальной гипертонией // В сборнике: Современные траектории развития социальной сферы: образование, опыт, проблемы, наука, тенденции, перспективы. 2017. С. 154-158.

26. Яскевич Р.А., Давыдов Е.Л. Подходы к обучению в «школе пациента с артериальной гипертонией» в пожилом и старческом возрасте и их влияние на качество жизни // Международный журнал прикладных и фундаментальных исследований. 2016. № 12-1. С. 66-70.

27. Яскевич Р.А., Деревянных Е.В., Поликарпов Л.С. и др. Оценка качества жизни у пожилых мигрантов Крайнего Севера в период реадаптации к новым климатическим условиям // Успехи геронтологии. 2013. Т. 26; № 4. C. 652-657.

28. Яскевич Р.А., Москаленко О.Л. Анализ частоты и структуры заболеваний сердечно-сосудистой системы у мигрантов Крайнего Севера в период реадаптации к новым климатическим условиям // В мире научных открытий. 2017. T. 9. № 4-2. C. 41-58. 
29. Artyukhov I.P., Grinshtein Y.I., Petrova M.M. et al. Prevalence of arterial hypertension in the Krasnoyarsk Krai (Siberia, Russia) // BMC Cardiovascular Disorders. 2017. Vol. 17(1). P. 138.

30. Mills K.T., Bundy J.D., Kelly T.N. et al. Global disparities of hypertension prevalence and control: a systematic analysis of population-based studies from 90 countries // Circulation. 2015. Vol. 134, pp. 441-450.

31. Theodorou M., Kaitelidou D., Galanis P., et al. Quality of Life Measurement in Patients with Hypertension in Cyprus // Hellenic J. Cardiol. 2011. Vol. 52, pp. 407-415.

32. Wan C., Jiang R., Tu X.M., et al. The hypertension scale of the system of Quality of Life Instruments for Chronic Diseases, QLICD-HY: a development and validation study // Int J. Nurs Stud. 2012. Vol. 49. №4, pp. 465-480.

33. World Health Organization. Cardiovascular diseases (CVDs) - Fact sheet. 2017. [Cited 4 Sep 2017.] Available from URL: http://www.who.int/mediacentre/factsheets/fs317/en/.

34. Yaskevich R.A., Moskalenko O.L. Analysis of the incidence and structure of the cardiovascular system diseases in the far north migrants over the period of readaptation to the new climatic conditions // В мире научных открытий. 2017. T. 9. № 4-2, pp. 59-73.

35. Yaskevich R.A., Polikarpov L.S., Gogolashvili N.G. et al. Estimation of the quality of life in elderly migrants of the Far North in the period of readaptation to new climatic conditions // Advances in Gerontology. 2014. T. 4. № 3, pp. 213-217.

\section{References}

1. Artyukhov I.P., Davydov E.L., Kapitonov V.F., Khar'kov E.I. Sotsial'no-ekonomicheskaya kharakteristika bol'nykh s arterial'noy gipertoniey starshikh vozrastnykh grupp [Socio-economic characteristics of patients with arterial hypertension of older age groups]. Sibirskoe meditsinskoe obozrenie [Siberian Medical Review]. 2013. №6, pp. 78-83.

2. Belyaeva A.K., Mul'tanovskiy B.L., Shabardina S.V. i dr. Effektivnost' raboty shkoly zdorov'ya dlya patsientov s arterial'noy gipertoniey [Efficiency of the School of Health for Patients with Arterial Hypertension]. Zdorov'e, demografiya, ekologiya finno-ugorskikh narodov [Health, Demography, Ecology of Finno-Ugric Peoples]. 2013. №4, pp. 29-31.

3. Vologdina I.V., Fedorets V.N., Poroshina E.G. Otsenka psikhosomaticheskikh osobennostey i kachestva zhizni u patsientov starcheskogo vozrasta s khronicheskoy serdechnoy nedostatochnost'yu [Assessment of psychosomatic features and quality of life in patients of senile age with chronic heart failure]. Klinicheskaya bol'nitsa [Clinical Hospital]. 2012. № 2-3, pp. 45-48. 
4. Vologdina I.V., Min'ko B.A., Krylova M.P., Poroshina E.G. Kachestvo zhizni i trevozhno-depressivnye narusheniya $u$ bol'nykh pozhilogo vozrasta s fibrillyatsiey predserdiy [Quality of life and anxiety-depressive disorders in elderly patients with atrial fibrillation]. Vestnik Mezhnatsional'nogo tsentra issledovaniya kachestva zhizni [Bulletin of the Interethnic Center for Quality of Life Research]. 2016. № 27-28, pp. 37-43.

5. Garganeeva N.P., Petrova M.M., Evsyukov A.A. i dr. Vliyanie depressii na techenie ishemicheskoy bolezni serdtsa i kachestvo zhizni patsientov [Influence of depression on the course of coronary heart disease and quality of life of patients]. Klinicheskaya meditsina [Clinical Medicine]. 2014. № 12, pp. 30-37.

6. Davydov E.L., Goryanets D.I., Kozhevnikov I.A. i dr. Osobennosti predstavleniy o problemakh zhizni s arterial'noy gipertoniey patsientov starshikh vozrastnykh grupp [Peculiarities of ideas about life problems with arterial hypertension in patients of older age groups]. Meditsinskiy vestnik MVD [Medical Bulletin of the Ministry of Internal Affairs]. 2012. № 5 (60), pp. 25-30.

7. Davydov E.L., Yaskevich R.A., Kusaev V.V., Alekseev I.A. Problemy priverzhennosti $k$ lecheniyu patsientov starshikh vozrastnykh grupp s arterial'noy gipertoniey v g. Krasnoyarske v ramkakh organizatsionno-funktsional'noy modeli mediko-sotsial'noy pomoshchi [Problems of adherence to treatment of patients of older age groups with arterial hypertension in Krasnoyarsk within the framework of the organizational and functional model of medical and social care]. Mezhdunarodnyy zhurnal eksperimental'nogo obrazovaniya [International Journal of Experimental Education]. 2016. № 5-3, pp. 285-289.

8. Davydov E.L., Yaskevich R.A., Mazharov V.F. Faktory, prepyatstvuyushchie priobreteniyu patsientami starshikh vozrastnykh grupp lekarstvennykh sredstv dlya lecheniya arterial'noy gipertonii [Factors hindering the acquisition by patients of older age groups of medicines for the treatment of arterial hypertension]. Mezhdunarodnyy zhurnal eksperimental'nogo obrazovaniya [International Journal of Experimental Education]. 2016. № 5-3, pp. 290-295.

9. Kadyrova D.A., Safokhonov D.T., Ganieva F.S., Ishankulova G.A. Kachestvo zhizni bol'nykh pozhilogo i starcheskogo vozrasta s arterial'noy gipertoniey [Quality of life of elderly and senile patients with arterial hypertension]. Sibirskiy meditsinskiy zhurnal (Irkutsk) [Siberian Medical Journal (Irkutsk)]. 2014. № 3, pp. 58-61.

10. Kornilova M.V. Kachestvo zhizni i sotsial'nye riski pozhilykh [Quality of life and social risks of the elderly]. Sovremennye issledovaniya sotsial'nykh problem [Modern research of social problems]. 2011. V. 7. №3, pp. 78-88.

11. Melekhin A.I. Kachestvo zhizni v pozhilom i starcheskom vozraste: problemnye voprosy [Quality of life in the elderly and senile age: problematic issues]. 
Sovremennaya zarubezhnaya psikhologiya [Contemporary foreign psychology]. 2016. V. 5. № 1, pp. 53-63.

12. Plavunov N.F., Fomina A.V. Izuchenie informirovannosti patsientov, poseshchayushchikh shkolu arterial'noy gipertonii, o svoem zabolevanii [Studying the awareness of patients visiting the school of arterial hypertension about their disease]. Vestnik Rossiyskogo universiteta druzhby narodov. Seriya: Meditsina [Bulletin of the Russian University of Peoples' Friendship. Series: Medicine]. 2004. № 2, pp. 81-82.

13. Pristupa E.N., Pavlova Yu.A. Issledovanie kachestva zhizni raznykh vozrastnykh grupp naseleniya [The study of the quality of life of different age groups of the population]. Nauka i sport: sovremennye tendentsii [Science and sport: modern trends]. 2013. V.1. № 1, pp. 12-21.

14. Remizov E.V., Davydov E.L., Korepina T.V. Problemy kachestva zhizni patsientov starshikh vozrastnykh grupp s arterial'noy gipertoniey [Problems of quality of life of patients of older age groups with arterial hypertension]. Voenno-meditsinskiy zhurnal [Military Medical Journal]. 2012. № 5. P. 64.

15. Tikhonova N.V., Dobretsova E.A., Astanina N.G., Il'yushenko V.M. Psikhologicheskiy aspekt kachestva zhizni pozhilogo naseleniya Krasnoyarskogo kraya [Psychological aspect of the quality of life of the elderly population of the Krasnoyarsk Territory]. Meditsina i obrazovanie v Sibiri [Medicine and education in Siberia]. 2014. № 4. P. 64.

16. Filimonova L.A., Davydov E.L., Yaskevich R.A. Psikhosomaticheskie problemy patsientov starshikh vozrastnykh grupp s arterial'noy gipertoniey [Psychosomatic problems of patients of older age groups with arterial hypertension]. Sovremennye problemy nauki i obrazovaniya [Modern problems of science and education]. 2016. № 3. P. 106.

17. Khar'kov E.I., Davydov E.L. Osobennosti kachestva zhizni i psikhologicheskie kharakteristiki bol'nykh pozhilogo vozrasta s zabolevaniyami serdechno-sosudistoy sistemy i puti korrektsii poslednikh [Peculiarities of quality of life and psychological characteristics of elderly patients with diseases of the cardiovascular system and ways of correction of the latter]. Rossiyskiy kardiologicheskiy zhurnal [Russian Cardiology Journal]. 2010. № 3(83), pp. 53-57.

18. Khar'kov E.I., Davydov E.L., Grinshteyn Yu.I., Kusaev V.V. Osobennosti farmakoterapii v pozhilom i starcheskom vozraste. Soobshchenie II [Features of pharmacotherapy in the elderly and senile age. Communication II]. Sibirskiy meditsinskiy zhurnal (Irkutsk) [Siberian Medical Journal (Irkutsk)]. 2010. V. 99. №8, pp. 174-177. 
19. Khar'kov E.I., Davydov E.L., Shul'min A.V. Pozhiloy patsient i arterial'naya gipertoniya: osobennosti techeniya i terapii (Soobshchenie I) [Elderly patient and arterial hypertension: features of the course and therapy (Report I)]. Sibirskoe meditsinskoe obozrenie [Siberian Medical Review]. 2010. № 3(63), pp. 3-8.

20. Khar'kov E.I., Davydov E.L., Shul'min A.V. Pozhiloy patsient i arterial'naya gipertoniya: osobennosti techeniya i terapii (Soobshchenie II) [Elderly patient and arterial hypertension: features of the course and therapy (Report II)]. Sibirskoe meditsinskoe obozrenie [Siberian Medical Review]. 2010. № 3(65), pp. 3-7.

21. Shul'min A.V., Tikhonova N.V., Averchenko E.A. i dr. Kachestvo zhizni naseleniya kak komponent perspektivnogo razvitiya munitsipal'nogo zdravookhraneniya [The quality of life of the population as a component of the prospective development of municipal public health]. Meditsina $v$ Kuzbasse [Medicine in the Kuzbass]. 2011. № 2, pp. 8-12.

22. Shupina M.I., Loginova E.N. Perspektivy ispol'zovaniya obrazovatel'nykh programm v nemedikamentoznoy korrektsii arterial'noy gipertonii [Prospects of using educational programs in non-drug correction of arterial hypertension]. Kazanskiy meditsin skiy zhurnal [Kazan Medical Journal]. 2007. V.88. №5. prilozhenie, pp. 160-164.

23. Shcherbakova E.M. Rossiya: predvaritel'nye demograficheskie itogi 2016 goda (chast' II) [Russia: preliminary demographic results of 2016 (Part II)]. Demoskop Weekly [Demoscope Weekly]. 2017. № 717-718, pp. 21-30.

24. Yaskevich R.A. Osobennosti pokazateley kachestva zhizni v razlichnye periody readaptatsii $\mathrm{k}$ novym klimaticheskim usloviyam u pozhilykh migrantov Kraynego Severa s arterial'noy gipertoniey [Features of quality of life indicators in different periods of readaptation to new climatic conditions in elderly migrants of the Far North with arterial hypertension]. Klinicheskaya gerontologiya [Clinical gerontology]. 2017. V. 23. № 9-10, pp. 81-83.

25. Yaskevich R.A., Davydov E.L. Mediko-sotsial'nye problemy kachestva zhizni gerontov s arterial'noy gipertoniey [Medico-social problems of the quality of life of Gerontians with arterial hypertension]. Sovremennye traektorii razvitiya sotsial'noy sfery: obrazovanie, opyt, problemy, nauka, tendentsii, perspektivy [Modern trajectories of development of the social sphere: education, experience, problems, science, trends, perspectives]. 2017, pp. 154-158.

26. Yaskevich R.A., Davydov E.L. Podkhody k obucheniyu v "shkole patsienta s arterial'noy gipertoniey" v pozhilom i starcheskom vozraste i ikh vliyanie na kachestvo zhizni [Approaches to training in the "school of a patient with arterial hypertension" in the elderly and senile age and their impact on the quality of life]. Mezhdunarodnyy zhurnal prikladnykh i fundamental'nykh issledovaniy [International Journal of Applied and Fundamental Research]. 2016. № 12-1, pp. 66-70. 
27. Yaskevich R.A., Derevyannykh E.V., Polikarpov L.S. i dr. Otsenka kachestva zhizni u pozhilykh migrantov Kraynego Severa v period readaptatsii k novym klimaticheskim usloviyam [Evaluation of the quality of life in elderly migrants of the Far North during the period of readaptation to new climatic conditions]. Uspekhi gerontologii [Successes of gerontology]. 2013. V. 26. № 4, pp. 652-657.

28. Yaskevich R.A., Moskalenko O.L. Analiz chastoty i struktury zabolevaniy serdechno-sosudistoy sistemy u migrantov Kraynego Severa v period readaptatsii $\mathrm{k}$ novym klimaticheskim usloviyam [Analysis of the frequency and structure of diseases of the cardiovascular system in the migrants of the Far North in the period of adaptation to new climatic conditions]. V mire nauchnykh otkrytiy [Siberian Journal of Life Sciences and Agriculture]. 2017. V. 9. № 4-2. P. 41-58.

29. Artyukhov I.P., Grinshtein Y.I., Petrova M.M. et al. Prevalence of arterial hypertension in the Krasnoyarsk Krai (Siberia, Russia). BMC Cardiovascular Disorders. 2017. Vol. 17(1). P. 138.

30. Mills K.T., Bundy J.D., Kelly T.N. et al. Global disparities of hypertension prevalence and control: a systematic analysis of population-based studies from 90 countries. Circulation. 2015. Vol. 134, pp. 441-450.

31. Theodorou M., Kaitelidou D., Galanis P., et al. Quality of Life Measurement in Patients with Hypertension in Cyprus. Hellenic J. Cardiol. 2011. Vol. 52, pp. 407-415.

32. Wan C., Jiang R., Tu X.M., et al. The hypertension scale of the system of Quality of Life Instruments for Chronic Diseases, QLICD-HY: a development and validation study. Int J. Nurs Stud. 2012. Vol. 49. №4, pp. 465-480.

33. World Health Organization. Cardiovascular diseases (CVDs) - Fact sheet. 2017. [Cited 4 Sep 2017]. http://www.who.int/mediacentre/factsheets/ fs317/en/

34. Yaskevich R.A., Moskalenko O.L. Analysis of the incidence and structure of the cardiovascular system diseases in the far north migrants over the period of readaptation to the new climatic conditions. V mire nauchnykh otkrytiy. 2017. V. 9. № 4-2, pp. 59-73.

35. Yaskevich R.A., Polikarpov L.S., Gogolashvili N.G. et al. Estimation of the quality of life in elderly migrants of the Far North in the period of readaptation to new climatic conditions. Advances in Gerontology. 2014. V. 4. № 3, pp. 213-217.

\section{ДАННЫЕ ОБ АВТОРАХ}

Алексеев Игорь Александрович, аспирант кафедры пропедевтики внутренних болезней и терапии 
ГБОУ ВПО «КрасГМУ им. проф. Ф.В. Войно-Ясенеикого» МЗ РФ ул. Партизана Железняка, 1а, г. Красноярск, 660022, Российская Федерация alexeevia@mail.ru

Харьков Евгений Иванович, заведующий кафедрой пропедевтики внутренних болезней и терапии, доктор медицинских наук, профессор ГБОУ ВПО «КрасГМУ им. проф. Ф.В. Войно-Ясенеикого» МЗ РФ ул. Партизана Железняка, 1а, г. Красноярск, 660022, Российская Федераиия harkov-50@mail.ru

Иванов Александр Геннадьевич, доцент кафедры пропедевтики внутренних болезней и терапии, кандидат медицинских наук, доцент ГБОУ ВПО «КрасГМУ им. проф. Ф.В. Войно-Ясенеикого» МЗ РФ ул. Партизана Железняка, 1а, г. Красноярск, 660022, Российская Федераиия ivanov-ag@list.ru

Яскевич Роман Анатольевич, доцент кафедры пропедевтики внутренних болезней и терапии, ведущий научный сотрудник группы патологии сердечно-сосудистой системы, кандидат медицинских наук, доцент

ГБОУ ВПО «КрасГМУ им. проф. Ф.В. Войно-Ясенеикого» МЗ РФ; Федеральное государственное бюджетное научное учреждение «Научно-исследовательский институт медииинских проблем Севера» ул. Партизана Железняка, 1а, г. Красноярск, 660022, Российская Федерация; ул. Партизана Железняка, 32, г. Красноярск, 660022, Российская Федерация cardio@impn.ru

Москаленко Ольга Леонидовна, старший научный сотрудник, кандидат биологических наук Федеральное государственное бюджетное научное учреждение «Научно-исследовательский институт медицинских проблем Севера» ул. Партизана Железняка, 32, г. Красноярск, 660022, Российская Федераичия gre-ll@mail.ru 


\section{DATA ABOUT THE AUTHORS}

Alekseev Igor Alexandrovich, Post-Graduate Student of the Department of Propaedeutics of Internal Diseases and Therapy

Krasnoyarsk State Medical University named after Professor V.F. Voino-Yasenetzkiy 1a, P. Zheleznyaka St., Krasnoyarsk, 660022, Russian Federation

alexeevia@mail.ru

Kharkov Evgeniy Ivanovich, Head of the Department of Propaedeutics of Internal Diseases and Therapy, Doctor of Medical Sciences, Professor Krasnoyarsk State Medical University named after Professor V.F. Voino-Yasenetzkiy 1a, P. Zheleznyaka St., Krasnoyarsk, 660022, Russian Federation harkov-50@mail.ru

Ivanov Aleksandr Gennadievich, Associate Professor at Department of Propedeutics of Internal Diseases and Therapy, Candidate of Medical Science, Docent

Krasnoyarsk State Medical University named after Professor V.F. Voino-Yasenetzkiy 1a, P. Zheleznyaka St., Krasnoyarsk, 660022, Russian Federation

ivanov-ag@list.ru

Yaskevich Roman Anatolyevich, Associate Professor at Department of Propedeutics of Internal Diseases and Therapy, Leading Researcher of the Group Pathology of the Cardiovascular System, Candidate of Medical Science, Docent

Krasnoyarsk State Medical University named after Professor V.F. Voino-Yasenetzkiy; Scientific Research Institute of medical problems of the North

1a, P. Zheleznyaka St., Krasnoyarsk, 660022, Russian Federation; 3g, P. Zheleznyaka St., Krasnoyarsk, 660022, Russian Federation cardio@impn.ru

Moskalenko Olga Leonidovna, Senior Researcher, Candidate of Biological Sciences

Scientific Research Institute of medical problems of the North 3g, P. Zheleznyaka St., Krasnoyarsk, 660022, Russian Federation gre-ll@mail.ru 